\title{
Mental Health Screening as the Standard of Care in Pediatric Inflammatory Bowel Disease
}

\author{
William E. Bennett Jr, MD1, MS 1,2; Marian D. Pfefferkorn, MD1
}

1 Division of Pediatric Gastroenterology, Hepatology, and Nutrition, Department of Pediatrics, Indiana University School of Medicine, Indianapolis

2 Division of Pediatric and Adolescent Comparative Effectiveness Research, Department of Pediatrics, Indiana University School of Medicine, Indianapolis

Corresponding Author: William E. Bennett Jr, MD, MS, Division of Pediatric Gastroenterology, Hepatology, and Nutrition, Department of Pediatrics, Indiana University School of Medicine, 410 W 10th St, Health Information and Translational Sciences 2037, Indianapolis, IN 46074 (webjr@iu.edu).

Butwicka and colleagues ${ }^{1}$ have published a fascinating, landmark cohort study in this issue of JAMA Pediatrics assessing the prevalence of psychiatric diagnoses and symptoms among children with inflammatory bowel disease (IBD) in Sweden. The authors used a rigorous design that compared a cohort of more than 6000 pediatric patients with IBD with hundreds of thousands of healthy controls, as well as a separate cohort comprising the patients' own siblings who did not have IBD. Butwicka et al ${ }^{1}$ computed hazard ratios for any psychiatric disorder, as well as for multiple specific disorders, and found a hazard ratio of 1.6 for any psychiatric diagnosis when comparing

This is the author's manuscript of the article published in final edited form as:

Bennett, W. E., \& Pfefferkorn, M. D. (2019). Mental Health Screening as the Standard of Care in Pediatric Inflammatory Bowel Disease. JAMA Pediatrics, 173(10), 919-921. https://doi.org/10.1001/jamapediatrics.2019.2669 
children with IBD with healthy controls. The statistical analysis is stellar and represents the best data we currently have on the intersection of pediatric IBD and mental health. Their study highlights a substantial risk in a vulnerable population and should trigger revision of guidelines and allocation of resources to support widespread screening and treatment for these dangerous conditions.

The authors' use of a comparison group of siblings that eliminates confounders present within families makes their findings particularly impactful. Because mental health diagnoses cluster within families and have strong social determinants, isolating a particular diagnosis such as IBD as the likely causative factor for a psychiatric disorder requires careful research design. The authors should be applauded for this effort, and we are very excited to see such rigorous study of this important problem.

An alternative explanation for their findings is that patients with a chronic illness such as IBD are more likely to receive a diagnosis, but they are not necessarily more likely to have the disorder. The authors used a single assignment of a psychiatric International Classification of Diseases code to define the presence of mental illness. Low sensitivity and specificity of International Classification of Diseases codes is the rule, and both have been found to be lower than $80 \%$ in psychiatric codes present in populations with other chronic diseases. ${ }^{2}$ Some of this phenomenon is probably explained by the concept of "diagnosis creep," where having 1 diagnosis of a chronic illness often results in the assignment of more diagnoses by physicians, irrespective of diagnostic validity. ${ }^{3}$

Unfortunately, to resolve this issue definitively would require a very large study with formal mental health screening (confirmed by a mental health practitioner) in a 
prospective pediatric cohort of patients with IBD, as well as matched healthy controls and siblings. This would be an enormous undertaking, and the magnitude of the findings by Butwicka et al1 make their results highly likely to represent reality.

In addition, the authors do not distinguish between mild and severe psychiatric disorders, as it is not possible based on their data source and study design. Mild depression, for instance, has a very high prevalence in adolescence ${ }^{4}$ as much as $33 \%$, and may not be associated with IBD care, overall morbidity, or risk of death nearly as much as severe cases of depression, where suicidal ideation is much more common. Finally, this study takes place in a single country with a single population that is largely genetically and culturally homogeneous, and in a system with high levels of health care access and a nationalized health care system. Although there is no reason to think that the correlation would not be present in other settings based on this finding alone, the IBD research community should continue to assess this phenomenon in other health care systems and populations.

Perhaps even more relevant to pediatric gastroenterologists and pediatricians, the study by Butwicka et al $^{1}$ found that the association between IBD and psychiatric diagnoses was stronger during childhood (a hazard ratio of 2.1 until 18 years of age compared with a hazard ratio of 1.6 during the entire study period, which extended into early adulthood for most individuals). Their findings thus strongly indicate a need for more focused intervention during adolescence, when patients appear to be even more vulnerable. Because suicide is the third leading cause of death in teenagers, and depression is the leading cause of morbidity, ${ }^{5}$ careful attention to these disorders in 
patients with IBD is paramount. An integrated mental health and digestive health model is the simplest, and best, solution.

There are numerous screening strategies for the equally numerous comorbidities in IBD that have become standard of care, with even lower hazard ratios than described in the study by Butwicka et $\mathrm{al}^{1}$ : tuberculosis screening in patients taking tumor necrosis factor inhibitors, ${ }^{6}$ screening for vitamin $\mathrm{D}$ deficiency and dual-energy $\mathrm{x}$-ray absorptiometry scans in children with Crohn disease, ${ }^{7}$ and iron deficiency screening, ${ }^{8}$ among many others. Overall, we have found the barriers to accomplishing such screening to be quite low and the cost is usually covered by payors. So, one would be hard pressed to find a patient taking a tumor necrosis factor inhibitor who did not undergo a screening test for tuberculosis, but it is doubtful that formal screening for depression and anxiety have been performed on these same patients, despite the fact that, especially in a region with a low prevalence of tuberculosis, patients are at much higher risk of suicide than they are of latent infection reactivated by a tumor necrosis factor inhibitor.

There is a strong precedent for integrating ancillary health services into IBD care. Presently, many pediatric IBD centers have integrated nutrition support, which clearly improves outcomes in patients at high risk for consequences of malnutrition. ${ }^{9}$ In addition, most centers have social work and care coordination as well, which are also clearly linked to improved clinical outcomes across many chronic conditions. ${ }^{10}$ However, as Butwicka et al1 clearly demonstrate in the present study, the risk for psychiatric disorders remains high, but the infrastructure we have in place to deal with these problems is utterly inadequate. Integrated mental health care has been shown to be highly effective at 
reducing the burden of mental health disease in primary care settings, ${ }^{11}$ but there has not been widespread adoption of this strategy either in primary care or pediatric subspecialty care, despite evidence for efficacy.

Inadequate integration is only a part of the systemic problem, though, because limited access to mental health services is endemic both in North America and elsewhere. There exists consistently inadequate access to mental health services in the general pediatric population ${ }^{12}$ as well as in specific vulnerable pediatric populations, including patients with $\mathrm{IBD},{ }^{13}$ those receiving public financial services, ${ }^{14}$ and racial/ethnic minorities. ${ }^{15}$ So one aspect of solving the high rate of psychiatric disorders in pediatric patients with IBD is improving access to mental health broadly across the health care system.

We suggest that regular screening for mental health disorders, especially depression and suicidal ideation, be instituted immediately in all children with IBD. Screening can be accomplished quickly, with minimal cost and disruption of clinic workflow. ${ }^{16}$ We have just completed a single-center comparative effectiveness study supported by the Agency for Healthcare Research and Quality and National Institutes of Health called the DECADES (Detecting and Evaluating Childhood Depression Effectively in Subspecialties) trial, which randomizes children who have positive screening results for anxiety or depression to receive either usual care or an immediate integrated mental health care visit after their gastroenterology visit. Our preliminary findings support the work of Butwicka et al, ${ }^{1}$ with a high rate of positive screening results and higher quality of life scores for those who receive integrated mental health care services. As a result, we 
have begun instituting more rigorous screening for anxiety and depression in our patients across multiple sites.

Mental health disorders are perhaps the greatest threat to life and happiness that young people face, especially those with chronic illness. Butwicka et al ${ }^{1}$ clearly show that childhood-onset IBD represents a particularly strong risk factor for mental health disorders. We therefore urge physicians and other stakeholders to institute mental health screening procedures and adequate integrated mental health care for children with IBD immediately and allocate resources to reduce this serious risk to life and health.

\section{REFERENCES}

1 Butwicka, A., Olén, O., Larsson, H., Halfvarson, J., Almqvist, C., Lichtenstein, P., Serlachius, E., Frisén, L., \& Ludvigsson, J. F. (2019). Association of ChildhoodOnset Inflammatory Bowel Disease With Risk of Psychiatric Disorders and Suicide 
$\begin{array}{llll}\text { Attempt. } & \text { JAMA } & \text { 969-978 }\end{array}$ https://doi.org/10.1001/jamapediatrics.2019.2662

2 Grassi, L., Sabato, S., Rossi, E., Marmai, L., Biancosino, B., \& Gatti, M. (2006). Depressive and anxiety disorders among cancer patients: Screening methods by using the Distress Thermometer compared to the ICD-10. 15, S162-S162. https://iris.unife.it/handle/11392/524737\#.XsVBFGhKhPY

3 Moynihan, $\quad$ R. (n.d.). Caution! Diagnosis creep. https://doi.org/10.18773/austprescr.2016.021

4 Lewinsohn, P. M., Hops, H., Roberts, R. E., Seeley, J. R., \& Andrews, J. A. (1993). Adolescent psychopathology: I. Prevalence and incidence of depression and other DSM-III-R disorders in high school students. Journal of Abnormal Psychology, 102(1), 133-144. https://doi.org/10.1037/0021-843X.102.1.133

5 WHO | Adolescent health epidemiology. (n.d.). WHO; World Health Organization. $\begin{array}{llll}\text { Retrieved } & \text { May } & 20, & \text { 2020, }\end{array}$ https://www.who.int/maternal child adolescent/epidemiology/adolescence/en/

6 Keane, J., Gershon, S., Wise, R. P., Mirabile-Levens, E., Kasznica, J., Schwieterman, W. D., Siegel, J. N., \& Braun, M. M. (2001). Tuberculosis Associated with Infliximab, a Tumor Necrosis Factor a-Neutralizing Agent. New England Journal of Medicine, 345(15), 1098-1104. https://doi.org/10.1056/NEJMoa011110

7 Sentongo, T. A., Semaeo, E. J., Stettler, N., Piccoli, D. A., Stallings, V. A., \& Zemel, B. S. (2002). Vitamin D status in children, adolescents, and young adults with 
Crohn disease. The American Journal of Clinical Nutrition, 76(5), 1077-1081. https://doi.org/10.1093/ajcn/76.5.1077

8 Wiskin, A. E., Fleming, B. J., Wootton, S. A., \& Beattie, R. M. (2012). Anaemia and iron deficiency in children with inflammatory bowel disease. Journal of Crohn's and Colitis, 6(6), 687-691. https://doi.org/10.1016/j.crohns.2011.12.001

9 Day, A. S., Whitten, K. E., Sidler, M., \& Lemberg, D. A. (2008). Systematic review: Nutritional therapy in paediatric Crohn's disease. Alimentary Pharmacology \& Therapeutics, 27(4), 293-307. https://doi.org/10.1111/j.1365-2036.2007.03578.x

10 Peikes, D., Chen, A., Schore, J., \& Brown, R. (2009). Effects of Care Coordination on Hospitalization, Quality of Care, and Health Care Expenditures Among Medicare Beneficiaries: 15 Randomized Trials. JAMA, 301(6), 603-618. https://doi.org/10.1001/jama.2009.126

11 Butler, M., Kane, R. L., McAlpine, D., Kathol, R. G., Fu, S. S., Hagedorn, H., \& Wilt, T. J. (2008). Integration of mental health/substance abuse and primary care. Evidence Report/Technology Assessment, 173, 1-362.

12 Owens, P. L., Hoagwood, K., Horwitz, S. M., Leaf, P. J., Poduska, J. M., Kellam, S. G., \& lalongo, N. S. (2002). Barriers to Children's Mental Health Services. Journal of the American Academy of Child \& Adolescent Psychiatry, 41(6), 731738. https://doi.org/10.1097/00004583-200206000-00013

13 Rogala, L., Miller, N., Graff, L. A., Rawsthorne, P., Clara, I., Walker, J. R., Lix, L., Ediger, J. P., McPhail, C., \& Bernstein, C. N. (2008). Population-based controlled study of social support, self-perceived stress, activity and work issues, and access 
to health care in inflammatory bowel disease. Inflammatory Bowel Diseases, 14(4), 526-535. https://doi.org/10.1002/ibd.20353

14 Burns, B. J., Phillips, S. D., Wagner, H. R., Barth, R. P., Kolko, D. J., Campbell, Y., \& Landsverk, J. (2004). Mental Health Need and Access to Mental Health Services by Youths Involved With Child Welfare: A National Survey. Journal of the American Academy of Child \& Adolescent Psychiatry, 43(8), 960-970. https://doi.org/10.1097/01.chi.0000127590.95585.65

15 Sentell, T., Shumway, M., \& Snowden, L. (2007). Access to Mental Health Treatment by English Language Proficiency and Race/Ethnicity. Journal of General Internal Medicine, 22(2), 289-293. https://doi.org/10.1007/s11606-0070345-7

16 Harpham, T., Reichenheim, M., Oser, R., Thomas, E., Hamid, N., Jaswal, S., Ludermir, A., \& Aidoo, M. (2003). Measuring mental health in a cost-effective manner. Health Policy and Planning, 18(3), 344-349. https://doi.org/10.1093/heapol/czg041 